\title{
Assessing the knowledge and perceptions of medical students from the Western Cape, South Africa, regarding the Millennium Development Goals
}

\author{
Yeatman T, BSc(Dietetics) \\ Koen N, BSc(Dietetics), M(Nutrition) \\ De Ridder L, BSc(Dietetics) \\ Fenn B, BSc(Dietetics) \\ Wormsbacher L, BSc(Dietetics) \\ Daniels L, BSc(Dietetics), M(Nutrition) \\ Division of Human Nutrition, Faculty of Health Sciences, Stellenbosch University \\ Correspondence to: Toni-Lee Yeatman, e-mail: tonilee.yeatman@yahoo.com \\ Keywords: Millennium Development Goals, medical students, Western Cape, knowledge, perceptions
}

\begin{abstract}
Background: Health science students are key players in implementing the Millennium Development Goals (MDG). Knowledge and understanding at university level is essential to achieve the goals by 2015. The primary objective of this study was to assess the knowledge and perceptions of fifth-year medical students at Stellenbosch University and the University of Cape Town regarding the MDG. The secondary objectives were to determine the degree to which students are involved in awareness campaigns and implementation of the MDG, and to assess students' perceptions regarding the need for the MDG in South Africa.
\end{abstract}

Method: This observational, descriptive, cross-sectional study collected quantitative data. A census was carried out. All participants completed a self-administered questionnaire.

Results: Of the 176 participants, $61.14 \%$ said they had previously heard or read about the MDG. Forty per cent had heard about the MDG through awareness campaigns. More than half (54.86\%) claimed to know what the MDG were, but could not name all of the goals. Participants identified a mean of three out of eight MDG correctly. The majority of students considered MDG implementation in South Africa important but ineffective (69.85\%), and $85.82 \%$ believed that the MDG would not be achieved on time.

Conclusion: It was found that fifth-year medical students in the Western Cape were not adequately informed about the MDG and their importance in South Africa. However, their perceptions were positive, in that the majority agreed that the implementation of the MDG in South Africa is important and that more needs to be done in creating awareness about the goals.

(P) Peer reviewed. (Submitted: 2011-04-05. Accepted: 2011-09-01.) ๑ SAAFP

S Afr Fam Pract 2012;54(2):126-131

\section{Introduction}

Eight Millennium Development Goals (MDG), each with specific targets, were formulated at the Millennium Summit in 2000, facilitated by the United Nations (UN). ${ }^{1}$ These goals address current health, social and environmental issues worldwide, and are aimed to be achieved by 2015. ${ }^{1,2}$

The goals are the following:

- Goal 1: Eradicate extreme poverty and hunger

- Goal 2: Achieve universal primary education

- Goal 3: Promote gender equality

- Goal 4: Reduce child mortality

- Goal 5: Improve maternal health

- Goal 6: Combat human immunodeficiency virus/acquired immunodeficiency syndrome (HIV/AIDS), malaria and other diseases
- Goal 7: Ensure environmental sustainability

- Goal 8: Develop global partnerships for development

One of the most important aspects that should be addressed in order to be able to reach the MDG in time is the lack of knowledge regarding these goals. Increased universal access to knowledge and new information, especially in the health sector, will improve the likelihood of reaching the MDG by 2015 . $^{3}$

Although young people make up nearly $20 \%$ of the world's population today, they remain the largest under-represented group concerning actions regarding the implementation of MDG. Youth involvement is essential in reaching the MDG targets as the young people of today are the future generation. ${ }^{4}$ 
Among those working in the health sector, there is a correlation between increased knowledge and the rate at which health problems are solved. Knowledge in general is therefore essential in order to achieve the goals. ${ }^{3}$ MDG awareness campaigns are tools that may be used to increase knowledge and participation regarding the MDG.

Universities have the means to promote a sense of social responsibility in students and to teach them to be openminded about global issues such as the MDG. ${ }^{5}$ They can therefore play an important role in achieving the targets by providing quality education to help increase human resources, and by supporting and improving research. ${ }^{6}$

South Africa has 23 state-funded tertiary institutions. ${ }^{7,8}$ The considerable number of students enrolled at these institutions show the need to raise awareness about the Millennium Development Campaign at the tertiary education level, for example, via youth-led projects. ${ }^{9}$ Tertiary institutions should educate students as well as the general public and government officials, on how to be involved in reaching the targets of the MDG. Eighteen of these institutions have a faculty of health sciences and seven offer MBChB. In the Western Cape, only the University of Cape Town (UCT) and Stellenbosch University (SU) offer this degree.

Training of medical students is a vital step in achieving the MDG. Knowledge and understanding of global health issues affect the quality of medical treatment of a patient. As good health is a key factor in the reduction of poverty, it is essential that graduates are aware of the MDG. ${ }^{10-12}$ If this step is not fulfilled successfully, it may jeopardise and/ or slow down the process by which these goals will be achieved.

The primary objective of the study was to assess the knowledge and perceptions of fifth-year medical students at SU and UCT regarding the MDG in general. The secondary objectives were to determine the degree to which the students were involved in awareness campaigns and implementation of the MDG, and to assess students' knowledge regarding the MDG and their perceptions regarding the need for the MDG in South Africa.

\section{Method}

\section{Study design}

An observational, descriptive, cross-sectional design was used, collecting quantitative data.

\section{Study population and sample size}

The total study population consisted of 357 fifth-year MBChB students from SU and UCT registered for 2009. A census was carried out. All students present at the time of data collection and who met the inclusion criteria were included. Students who were repeating any fifth-year modules, those who did not give consent to participate in the study, and those who did not attend class on the day of data collection were excluded from the study.

\section{Data collection}

Data collection took place in the third and fourth weeks of January 2009 at UCT and SU. Data were collected by means of a self-administered questionnaire, at an allocated time and venue at the respective universities before the start of a scheduled class. Participants were not aware before the start of the class that they would be requested to take part in a research study. Before handing out the questionnaires the researchers gave a brief overview of the study, explained what was expected of the participants and that participation was voluntary. The researchers were present during questionnaire completion. The 20-minute questionnaire was available in English and Afrikaans. Completing the questionnaire implied informed consent and anonymity was ensured by not including questions of a personal or identifying nature.

The questionnaire consisted of four sections, with a total of twenty questions. It included questions to determine participants' demographics, general knowledge about the MDG, specific knowledge about the MDG, and questions in the form of Likert scales regarding participants' perceptions towards the need for the MDG. There were seventeen closed-ended questions and one open-ended question as well as two closed-ended questions with an additional option for comments.

\section{Pilot study}

A pilot study was conducted in January 2009 on a conveniently chosen sample of seventeen sixth-year $\mathrm{MBChB}$ students from one university. A venue and time was arranged, and the same method of data collection used in the main study was applied.

The purpose of the pilot study was to determine the face and content validity of the questionnaire. Face validity was determined by asking students participating in the pilot study to complete the questionnaire and then a questionnaire evaluation form that consisted of questions relating to the language and font used, the clarity of the questions and the length of the questionnaire. Content validity was determined by asking two independent dieticians in the field of community nutrition with experience in the MDG to comment on the appropriateness of the questions asked. Changes were then made to the questionnaire according to the students' and dieticians' recommendations. 


\section{Data analysis}

Microsoft Office Excel ${ }^{\circledast} 2003^{13}$ was used for the statistical analysis. Mainly descriptive statistics such as frequency tables, means, standard deviations, medians and quartiles of ordinal data were used.

\section{Ethics and legal aspects}

The study was approved by the Undergraduate Research Committee of the Division of Human Nutrition as well as the Health Research Ethics Committee, Faculty of Health Sciences, Stellenbosch University, and the Research Ethics Committee, Faculty of Health Sciences, University of Cape Town in 2008.

\section{Results}

Forty-nine per cent $(n=176)$ of the total study population $(n=357)$ took part in the study and completed the selfadministered questionnaire. Six questionnaires were excluded because these participants only completed the demographics section of the questionnaire. Of all the participants present on the day of data collection, none refused to take part in the study. For the purpose of data analysis, questionnaires from both universities were pooled. Owing to some participants not completing all questions in the knowledge and perception sections of the questionnaire, the $n$ values vary throughout this section.

\section{Demographic characteristics}

The study population $(n=176)$ consisted of 55 males $(31.25 \%)$ and 121 females (68.75\%). The mean age was 22.55 [standard deviation (SD) 1.25] years.

\section{Knowledge regarding the MDG}

Of the participants $(n=175), 61.71 \%$ indicated that they had heard or read about the MDG. Participants who indicated that they had heard or read about the MDG $(n=108)$ were asked to identify the media sources through which they were informed. Participants were allowed to choose more than one media source. Awareness campaigns (40.21\%) were highlighted as the main source of information, followed by lectures and class notes (29.90\%). Other sources included family and friends, newspapers, television, the internet, radio, magazines and campus notice boards.

Only $46.24 \%$ of participants $(n=173)$ reported that the MBChB programme at their university provided MDG information. Of these students $(n=80), 57.50 \%$ reported that the MDG were briefly mentioned in lectures or notes, $32.50 \%$ said they had received a brief overview, 3.75\% said they had a brief discussion in class and only $6.25 \%$ reported that the MDG were explained in detail.
Of the study population $(n=176), 42$ participants $(23.86 \%)$ had studied another course before MBChB. Participants with previous tertiary education obtained an average knowledge score of $26.59 \%$ while those without scored $26.85 \%$. This indicates that participants with prior education did not have more knowledge regarding the MDG than those without.

Participants were asked to rate, in their opinions, their knowledge of the MDG on a scale of zero to three, where zero indicated no knowledge about the MDG and three indicated that participants could name each MDG and its targets. Table I indicates that more than half of the participants (54.86\%) thought that they knew what the MDG were about, but could not name all of the goals.

Table I: Participants' opinions regarding the extent of their knowledge about Millennium Development Goals (MDG; $n=175$ )

\begin{tabular}{|c|c|c|c|}
\hline \multicolumn{2}{|c|}{ Score } & $\mathbf{n}$ & $\%$ \\
\hline 0 & "I do not know anything about the MDG" & 72 & 41.14 \\
\hline 1 & $\begin{array}{l}\text { "I know what the MDG are about, but cannot name } \\
\text { all of the goals" }\end{array}$ & 96 & 54.86 \\
\hline 2 & "I can name all of the MDG" & 6 & 3.43 \\
\hline 3 & "I can name each goal and its targets" & 1 & 0.57 \\
\hline
\end{tabular}

The questionnaire contained four questions testing participants' basic knowledge about the MDG. A maximum score of 11 could be obtained. The first question was to determine whether participants knew that the MDG were established in the year 2000. Of the 176 participants, only one $(0.57 \%)$ answered this question correctly. Participants were also asked the year in which the MDG were intended to be achieved. Only 14 participants $(7.95 \%)$ gave the correct answer, it being the year 2015. When asked how many MDG there were, only 22 participants (12.50\%) knew that there are eight.

In the final knowledge question, participants were given a list of 16 goals and were asked to identify the eight correct $M D G$ from the list. Participants were also given the option of indicating that they could not identify the correct eight in order to prevent answers being guessed. Only 3.98\% of the 176 participants identified all eight MDG correctly, whereas $46.02 \%$ did not know any of the MDG. On average, participants identified three out of the eight MDG correctly.

The total scores for the knowledge section were divided into four categories according to the total percentage achieved by each student. Figure 1 indicates that $50.57 \%$ of the participants achieved $0-24.90 \%$ and only $5.11 \%$ of participants achieved $75-100 \%$. The mean score of all the participants $(n=176)$ was $26.65 \%$. 


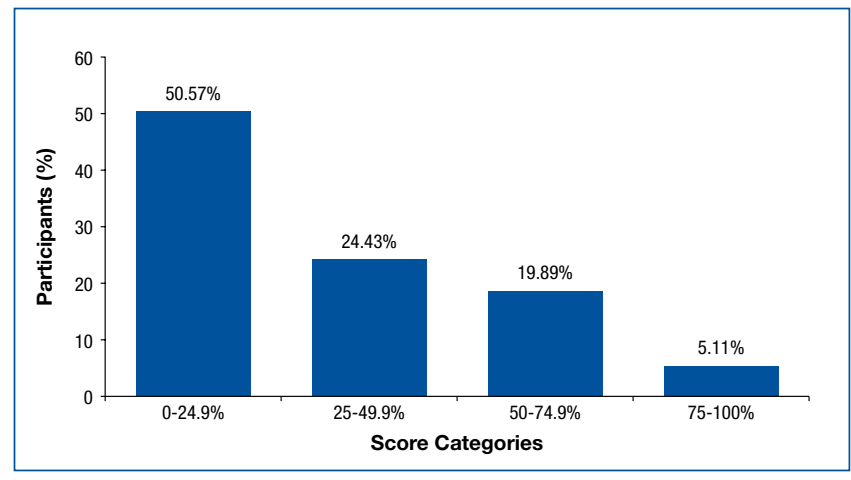

Figure 1: Knowledge section scores divided into four percentage categories $(n=176)$

\section{Involvement in awareness campaigns}

Participants who had been involved in MDG awareness campaigns generally obtained higher average knowledge scores than those who had not. The average knowledge score obtained by participants involved in MDG awareness campaigns ( $n=13$ ) was $53.15 \%$, while an average score of $25.16 \%$ was obtained by those not involved in awareness campaigns ( $n=159)$. Of those who had been involved in campaigns, $53.85 \%$ scored above $50 \%$ in the knowledge section, while only $23.27 \%$ of those who had not been involved scored above $50 \%$.

\section{Perceptions regarding the role of and need for the MDG}

Participants' perceptions regarding the success of implementation and importance of the MDG were sought using a range of questions framed on a Likert scale. Most of the participants $(96.64 \%)$ agreed or strongly agreed that MDG implementation in South Africa is important $(\mathrm{n}=$ 149) while $69.85 \%$ either disagreed or strongly disagreed that MDG implementation in South Africa is effective ( $n=$ 136). The vast majority (85.82\%) of participants $(n=141)$ either disagreed or strongly disagreed that the MDG will be achieved on time.

Figure 2 illustrates the participants' perceptions of the adequacy of MDG awareness in South Africa $(n=166)$ and

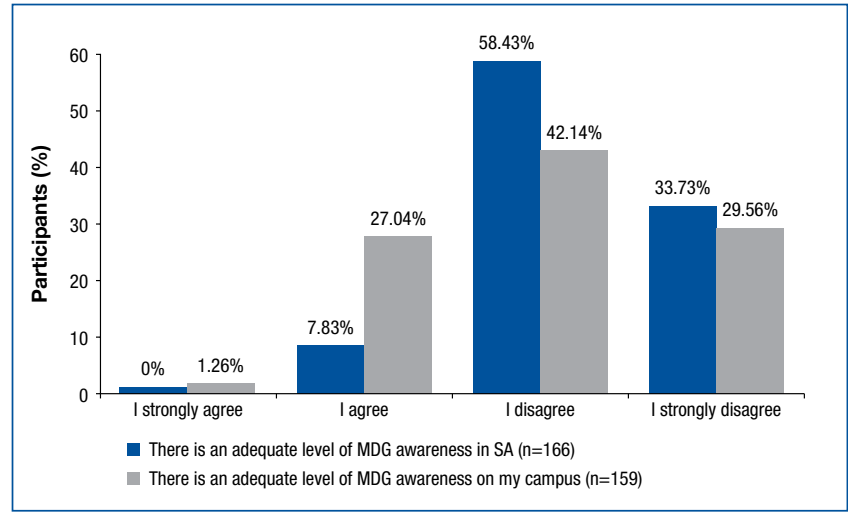

Figure 2: Participants' perceptions of the adequacy of MDG awareness in South Africa $(n=166)$ and on participants' university campus $(n=159)$ on their university campus ( $n=159)$. The graph indicates that the majority of participants $(92.16 \%$ and $71.70 \%$, respectively) perceive MDG awareness to be inadequate both on their university campus and in South Africa.

Figure 3 shows the media sources recommended by participants $(n=145)$ as sources of MDG awareness for university students. The results illustrate that participants thought that "awareness campaigns/posters" and "lectures/ class notes from university" would be most appropriate to raise MDG awareness among university students. The media sources "magazines" and "family/friends" were considered least appropriate.

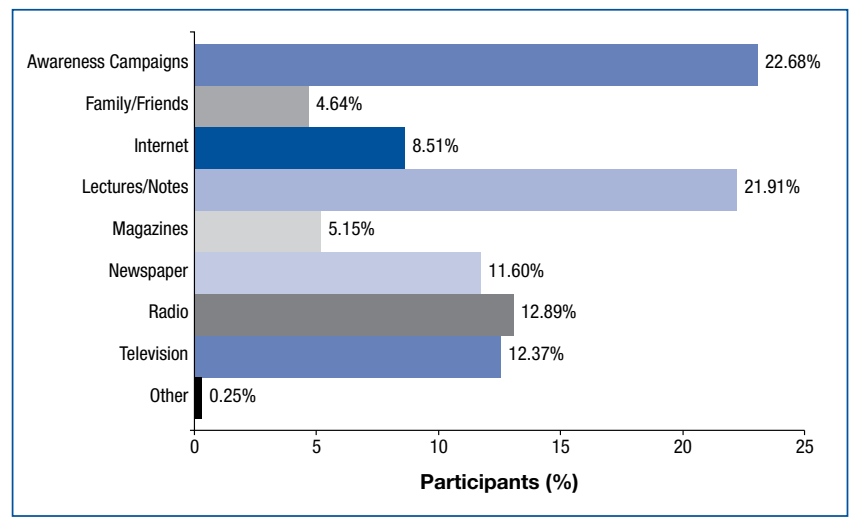

Figure 3: Recommended sources of MDG awareness for university students $(n=145)$

\section{Discussion}

This study was the first to be carried out in the Western Cape to determine medical students' knowledge and perceptions regarding the MDG. Participants were fifth-year MBChB students studying at SU and UCT.

It was found that participants had insufficient knowledge about the MDG. The results also showed, however, that involvement in creating MDG awareness is associated with increased MDG knowledge. This corresponds with the results of a survey carried out by the Global Youth Action Network, where young people clearly stated that they knew little to nothing about the MDG, and those who were involved in volunteer work had more knowledge than those who were not. ${ }^{4} A$ reason for this could be that students obtain more MDG information while being involved in awareness campaigns. Practical application of the MDG, knowledge and increased exposure to the MDG could lead to an increased responsibility in educating others. This could improve the spreading of knowledge, as young people are effective in distributing knowledge. This again highlights the fact that, in order to achieve the MDG in time, there is a need for more MDG awareness. Participants confirmed this: the majority indicated that they consider 
MDG awareness important and that more should be done to create awareness. However, it is important to note that participants who indicated that they were involved in MDG awareness campaigns may have already had an increased knowledge of the MDG and therefore chose to get involved in these campaigns to begin with.

The study also found that although $61.14 \%$ of participants had previously heard or read about the MDG, the average knowledge score obtained was only $26.65 \%$. This could indicate that although MDG awareness is being raised, the method of delivery may not be effective or the content may be insufficient. This correlates with the findings from an online consultation about the MDG in 2004. Most of those participants said that they had little knowledge about the MDG and also emphasised that they did not have access to tools for implementation. ${ }^{4}$ Therefore, there is a definite need for increasing MDG awareness among young people, with specific emphasis on providing tools such as internet access, adult mentors, opportunities for volunteerism, education and general support, and encouragement from government institutions (including resources and funding), so that youth are motivated to work together in improving their communities. ${ }^{4}$

Universities have the means to promote a sense of social responsibility in students and to teach them to be openminded about global issues such as the MDG ${ }^{5}$ and may therefore play an important role by providing quality education to increase human resources needed to achieve the goals. ${ }^{6}$ Interestingly, more than half of the participants $(53.76 \%)$ in this study claimed that the MDG were not included in their course, yet "lectures/notes from university" was rated second highest as an effective media source for raising MDG awareness among medical students and was also one of the top two media sources through which students indicated they learnt about the MDG. This could indicate that the relevant universities need to increase the amount of MDG information in lectures. However, universities may already provide MDG information, but reasons such as participants being absent from class or lack of concentration could account for participants' unawareness.

The University of Queensland (Australia) recommends including a module on the MDG into the health science curricula to increase students' knowledge regarding the goals and equip them with the skills necessary to tackle the MDG. ${ }^{10}$ It was found that medical students' knowledge regarding the MDG was generally poor. Our results correlate with those of a similar survey conducted among Australian medical students, where the surveyors found that only $32 \%$ of the respondents reported that they had heard about the MDG and knew something about them. ${ }^{14}$ As health science students are key players in implementing the MDG, knowledge and understanding at university level is an important step in achieving the goals by 2015. If this step is not fulfilled successfully, it may slow down the process by which these goals will be achieved in South Africa.

\section{Study limitations}

Of the 357 students registered for MBChB year V in 2009, only 176 students participated in the study. The small sample size was a result of students' absence from class on the days of data collection at the respective universities. Students at one university were also divided into different work groups and did not attend lectures at the time of data collection, which made them less accessible.

Owing to logistical reasons, the researchers could not include medical students from all South African universities and therefore only the universities in the Western Cape that offer the MBChB programme were included in this study.

\section{Recommendations}

For further research on this topic, the participants involved in the pilot study should include students from all universities and it is recommended that a larger study sample be included in follow-up studies. Further studies could focus on assessing knowledge and perceptions of students at other tertiary institutions, in different year groups, of other allied health sciences as well as other non-health science courses. The researchers also recommend that in future studies the curriculum should be investigated to establish which methods of education are used and to determine areas requiring improvement.

Although knowledge plays an important role in achieving health goals, it is necessary to note that in order to help achieve the MDG, knowledge needs to be translated into action. ${ }^{15}$ It is recommended that in addition to teaching about the MDG, information regarding health systems and system strengthening should also be included in health science curricula.

The findings of this study have highlighted that there is a need for MDG awareness campaigns on medical campuses in South Africa in order to facilitate their future success. To increase students' knowledge about the MDG, universities should provide more detailed information on the MDG and also review their current methods of presenting this. It is recommended that interactive methods of education be used as they have been shown to be more effective than didactic methods. ${ }^{16}$ The researchers also recommend that universities run campaigns on a more regular basis, and projects in which students can get actively involved, with the one goal of contributing to the achievement of the MDG. 


\section{Conclusion}

It was found that the fifth-year medical students at SU and UCT are not adequately informed about the MDG and their importance in South Africa. However, their perceptions were positive, in that the majority agreed that the implementation of the MDG in South Africa is important and that more needs to be done in creating awareness about the MDG. The lack of knowledge regarding the MDG here is, however, of great concern as these students are the future health professionals of South Africa and they are considered potential key players in implementing the MDG.

\section{Acknowledgements}

The authors would like to acknowledge Dr PJ van Deventer for the statistical analysis of the data.

\section{Declarations}

The authors declared no personal or financial conflict of interest that may have inappropriately influenced them in conducting this study.

\section{References}

1. United Nations Development Programme South Africa [homepage on the Internet]. c2010 [cited 2011 Apr 3]. Available from: http://www.undp.org.za/ the-country-programme

2. Bernier Q, Chimphango A, Ngocozela T, Environmental Monitoring Group. The Millennium Development Goals. A guide for South African civil society. South African Regional Poverty Network [homepage on the Internet]. c2005 [cited 2011 Mar 3]. Available from: http://www.sarpn.org.za/documents/d0002045/index.php

3. Travis P, Bennett S, Haines A, et al. Overcoming health-systems constraints to achieve the Millennium Development Goals. Lancet 2004;364:900-906.
4. The United Nations. Youth and the Millennium Develoment Goals Report 2005: Challenges and opportunities for implementation [document online]. c2005 [cited $2011 \mathrm{Apr}$ 4]. Available from: http://tig.phpwebhosting.com/themes/mdg/ YouthMDG.pdf

5. What university, college and cégep administrations can do. 8goals.ca [homepage on the Internet]. No date [cited 2010 Sep 20]. Available from: http://www.8goals. $\mathrm{ca} / \mathrm{site} / ? \mathrm{q}=$ node/77

6. Hassan MHA. African Universities and their role in development [Microsoft PowerPoint presentation]. No date [cited 2010 Sep 20]. Available from: http:// www.foundation-partnership.org/pubs/leaders/assets/papers/HassanSession1. ppt

7. South Africa: Overview. Council on Higher Education and Higher Education Quality Committee [homepage on the Internet]. c2009 [cited 2011 Mar 30]. Available from: http://www.che.ac.za/heinsa/overview/

8. Higher Education South Africa (HESA) [home page on the Internet]. No date [cited $2011 \mathrm{Mar}$ 30]. Available from: http://www.hesa.org.za

9. Youth - a vital role to play. Uneca.org [homepage on the Internet]. c2005 [cited 2010 Sep 20]. Available from: http://www.uneca.org/MDG/story6september05. asp

10. Fernanda C, Doran C, Lopez A, Taylor R. Developing world health: 1. Health and the Millennium Development Goals. University of Queensland [homepage on the Internet]. No date [cited 2011 Aug 25]. Available from: http://www2.som.uq.edu. au/som/CurrentStudents/globalhealth/Pages/TeachingandLearning.aspx

11. Tamsma N, Berman PC. The role of the health care sector in tackling poverty and social exclusion in Europe. European Health Management Association December [homepage on the Internet]. c2004 [cited 2011 Aug 25]. Available from: http:// www.ehma.org/files/EHMA\%20Poverty\%20Social\%20Exclusion\%20Report.pdf

12. Godlonton S, Keswell M. The impact of health on poverty: evidence from the South African integrated family survey. University of Cape Town: Centre for Social Science Research [homepage on the Internet]. c2004 [cited 2011 Aug 25]. Available from: http://www.cssr.uct.ac.za/publications/working-paper/2004/081

13. Microsoft Office Excel 2003. Part of the Microsoft Office Professional edition. Copyright (C) 1985-2003. Redmond: Microsoft Corporation.

14. Hersch F, Negin J, Atik A, Parker J. Australian medical students unaware of global development goals. Aust N Z J Public Health. 2010;34:94-95.

15. Pablos-Mendez A, Chunharas S, Lansang MA, et al. Knowledge translation in global health. Bull World Health Organ. 2005;83:723.

16. Khan SK, Coomarasamy A. A hierarchy of effective learning and teaching to acquire competence in evidence-based medicine. BMC Med Educ. 2006:6:59. 